\title{
TODIM strategy for multi-attribute group decision making in trapezoidal neutrosophic number environment
}

\author{
Surapati Pramanik ${ }^{1}\left[\right.$ [ $\cdot$ Rama Mallick ${ }^{2}$
}

Received: 9 January 2019 / Accepted: 4 May 2019 / Published online: 18 May 2019

(c) The Author(s) 2019

\begin{abstract}
Many multi-attribute group decision-making (MAGDM) strategies have been introduced in the literature to deal with decisionmaking problems in uncertain environment. Many of them are based on fuzzy numbers and they are not able to cope with indeterminacy and inconsistency involving in decision making. In recent years, some neutrosophic multi-attribute group decision-making strategies have been successfully developed to deal with uncertainty, indeterminacy, and inconsistency in decision making. Among them, TODIM (an acronym in Portuguese of interactive and multiple attribute decision making) strategy based on prospect theory has received more attention due to its great performance in considering the bounded rationality of decision makers. In this paper, we develop a TODIM strategy to deal with multi-attribute group decisionmaking problem in trapezoidal neutrosophic numbers environment. To establish the TODIM strategy, we employ score function, accuracy function, and Hamming distance function for trapezoidal neutrosophic numbers. Lastly, we solve an illustrative numerical example to show the applicability and usefulness of the proposed strategy. A comparison analysis is also provided.
\end{abstract}

Keywords Trapezoidal neutrosophic number - Score function · Accuracy function · Multi-attribute group decision making · TODIM strategy

\section{Introduction}

In decision-making problem, we face situations where some alternatives need to be evaluated with respect to some criteria in an uncertain environment. Multi-attribute decisionmaking (MADM) strategy helps us to evaluate and select the best alternative. For example, to choose a mobile phone, a customer would analyze whether the mobile phone model satisfies attributes such as good features, affordable price, hardware capacity and customer care.

Smarandache proposed neutrosophic set [1] based on neutrosophy in 1998. In 2010, Wang et al. [2] put forward

Surapati Pramanik

sura_pati@yahoo.co.in

Rama Mallick

ramamallick23@gmail.com

1 Department of Mathematics, Nandalal Ghosh B.T. College, Panpur, P.O., Narayanpur, Dist, North 24 Parganas, Kolkata, West Bengal 743126, India

2 Department of Mathematics, Umeschandra College, Surya Sen Street, Kolkata, West Bengal 700012, India single-valued neutrosophic set (SVNS) to handle uncertain, indeterminate and inconsistent data. SVNS, its extension and several hybrid neutrosophic sets have been studied in various fields such as MADM [3-74], conflict resolution [75], image processing [76] and educational problem [77].

Ye [78] proposed trapezoidal neutrosophic number (TrNN) derived from SVNS and trapezoidal fuzzy number [79]. Deli and Subas [80] proposed a ranking strategy of TrNN and developed an MADM strategy. Liang et al. [81] defined score function, accuracy function and certainty function of single-valued trapezoidal neutrosophic number (SVTrNN) using center of gravity (COG). Biswas et al. [82] developed a value- and ambiguity-based ranking strategy for TrNNs and proposed an MADM strategy. Biswas et al. [83] established TOPSIS strategy for MADM in trapezoidal neutrosophic number ( $\mathrm{TrNN}$ ) environment. Pramanik and Mallick [84] developed a VIKOR strategy for a multi-attribute group decision making (MAGDM) in TrNN environment. Giri et al. [85] presented an MADM strategy in interval trapezoidal neutrosophic number environment.

TODIM [86] is one of the popular strategies to handle MAGDM in the neutrosophic environment. Qin et al. [87] 
developed the TODIM strategy for triangular intuitionistic fuzzy number. Wang and $\mathrm{Li}$ [88] developed a TODIM method for multi-valued neutrosophic number. In 2016, Zhang et al. [89] introduced a TODIM strategy with neutrosophic numbers. Pramanik et al. [90] established a TODIM strategy for neutrosophic cubic set environment. Pramanik et al. [91] grounded a TODIM strategy in bipolar neutrosophic set environment. To date, TODIM strategy in the TrNN environment has not been presented in the literature. To fill up this research gap, we develop a TODIM strategy to deal with MAGDM problems in TrNN environment. We also solve an MAGDM problem to explain the proposed TODIM strategy in the TrNN environment.

This paper is constructed as follows. In "Preliminaries", we briefly describe a few definitions of trapezoidal fuzzy number, single-valued trapezoidal neutrosophic number, score function, accuracy function and Hamming distance between two trapezoidal neutrosophic fuzzy numbers. In "TODIM strategy for solving MAGDM problem under TrNN environment", we briefly describe the extended TODIM strategy in the TrNN environment. In "Illustrative example", we solve an illustrative numerical example using the proposed TODIM strategy. In "Conclusion", we present the sensitivity analysis.

\section{Preliminaries}

In this section, we recall some basic definitions associated with neutrosophic set, trapezoidal neutrosophic set and TODIM strategy.

Definition 1 [2] Assume that $H$ is a universal set. A singlevalued neutrosophic set $B$ in $H$ is given by

$B=\left\{h,<T_{B}(h), I_{B}(h), F_{B}(h)>\mid h \in H\right\}$,

where $T_{B}(h): H \rightarrow[0,1], I_{B}(h): H \rightarrow[0,1]$ and $F_{B}(h):$ $H \rightarrow[0,1]$ with the condition $0 \leq T_{B}(h)+I_{B}(h)+F_{B}(h) \leq$ 3 for all $h \in H$.The functions $T_{B}(h), I_{B}(h)$ and $F_{B}(h)$ are, respectively, the truth membership function, the indeterminacy membership function and the falsity membership function of the set $B$.

Definition $2[79,80]$ Let $S$ be a trapezoidal neutrosophic number $(\operatorname{TrNN})$. Then, its truth membership function is

$T_{S}(z)=\left\{\begin{array}{ll}\frac{(z-k) t_{S}}{(l-k)}, & k \leq z<l \\ t_{S}, & l \leq z \leq m \\ \frac{(n-z) t_{S}}{(n-m)}, & m<z \leq n \\ 0, & \text { otherwise }\end{array}\right.$.
Its indeterminacy membership function is

$I_{S}(z)=\left\{\begin{array}{ll}\frac{(l-z)+\left(z-k^{\prime}\right) i_{S}}{\left(l-k^{\prime}\right)}, & k^{\prime} \leq z<l \\ i_{S}, & l \leq z \leq m \\ \frac{z-m+\left(n^{\prime}-z\right) i_{S}}{n^{\prime}-m}, & m<z \leq n^{\prime} \\ 1, & \text { otherwise }\end{array}\right.$.

Its falsity membership function is

$F_{S}(z)=\left\{\begin{array}{ll}\frac{l-z+\left(z-k^{\prime \prime}\right) f_{S}}{l-k}, & k^{\prime \prime} \leq z<l \\ f_{S}, & l \leq z \leq m \\ \frac{z-m+\left(n^{\prime \prime}-z\right) f_{S}}{n^{\prime \prime}-m}, & m<z \leq n^{\prime \prime} \\ 1, & \text { otherwise }\end{array}\right.$,

where $0 \leq T_{S}(z) \leq 1,0 \leq I_{S}(z) \leq 1,0 \leq F_{S}(z) \leq 1$ and $0 \leq T_{S}(z)+I_{S}(z)+F_{S}(z) \leq 3 ; k, l, m, n \in R$. Then $S=\left([k, l, m, n] ; t_{S}, i_{S}, f_{S}\right)$ is called a $\operatorname{TrNN}$.

If $0 \leq k \leq l \leq m \leq n$, then $m$ is called a positive $\operatorname{TrNN}$. If $k \leq l \leq m \leq n \leq 0$, then $S$ is called a negative TrNN. If $0 \leq k \leq l \leq m \leq n \leq 1$ and $T_{S}, I_{S}, F_{S} \in[0,1]$, then $X$ is called a normalized TrNN, which is used in this paper. The membership functions are presented in Fig. 1 .

Definition 3 [81] Let $H=[k, l, m, n]$ be a trapezoidal fuzzy number on $R$, and $k \leq l \leq m \leq n$; then, the center of gravity (COG) of $H$ is defined by:

$\operatorname{COG}(H)= \begin{cases}H & \text { if } k=l=m=n=H \\ \frac{1}{3}\left[k+l+m+n-\frac{m n-k l}{m+n-l-k}\right] & \text { otherwise. }\end{cases}$

Definition 4 [81] Let $g=\left\langle(k, l, m, n) ; T_{g}, I_{g}, F_{g}\right\rangle$ be a $\operatorname{TrNN}$. Then the score function $S(g)$, accuracy function $\operatorname{Ac}(g)$ and certainty function $E(g)$ of $\operatorname{TrNN}$ are defined by

$S(g)=\operatorname{COG}(H) \times \frac{\left(2+T_{g}-I_{g}-F_{g}\right)}{3}$,

$\operatorname{Ac}(g)=\operatorname{COG}(H) \times\left(T_{g}-F_{g}\right)$,

$E(g)=\operatorname{COG}(H) \times T_{g}$.

Here, $\operatorname{COG}(H)$ is defined in (5).

Definition 5 [81] Comparison of two TrNNs:

Let $g_{1}=\left\langle\left(k_{1}, l_{1}, m_{1}, n_{1}\right) ; T_{g_{1}}, I_{g_{1}}, F_{g_{1}}\right\rangle$ and $g_{2}=$ $\left\langle\left(k_{2}, l_{2}, m_{2}, n_{2}\right) ; T_{g_{2}}, I_{g_{2}}, F_{g_{2}}\right\rangle$ be any two TrNNs in $S$. The comparison between $g_{1}$ and $g_{2}$ is stated as follows:

1. If $\operatorname{Sc}\left(g_{1}\right)>\operatorname{Sc}\left(g_{2}\right)$, then $g_{1}>g_{2}$.

2. If $\operatorname{Sc}\left(g_{1}\right)=\operatorname{Sc}\left(g_{2}\right)$ and $\operatorname{Ac}\left(g_{1}\right)>\operatorname{Ac}\left(g_{2}\right)$, then $g_{1}>g_{2}$.

3. If $\operatorname{Sc}\left(g_{1}\right)=\operatorname{Sc}\left(g_{2}\right)$ and $\operatorname{Ac}\left(g_{1}\right)<\operatorname{Ac}\left(g_{2}\right)$, then $g_{1}<g_{2}$.

4. If $\operatorname{Sc}\left(g_{1}\right)=\operatorname{Sc}\left(g_{2}\right)$ and $\operatorname{Ac}\left(g_{1}\right)=\operatorname{Ac}\left(g_{2}\right)$, and $E\left(g_{1}\right)>E\left(g_{2}\right), g_{1}>g_{2}$ and when $E\left(g_{1}\right)<E\left(g_{2}\right)$, then $g_{1}$ $<g_{2}$ and $g_{1}>g_{2}$ when $E\left(g_{1}\right)=E\left(g_{2}\right)$. 


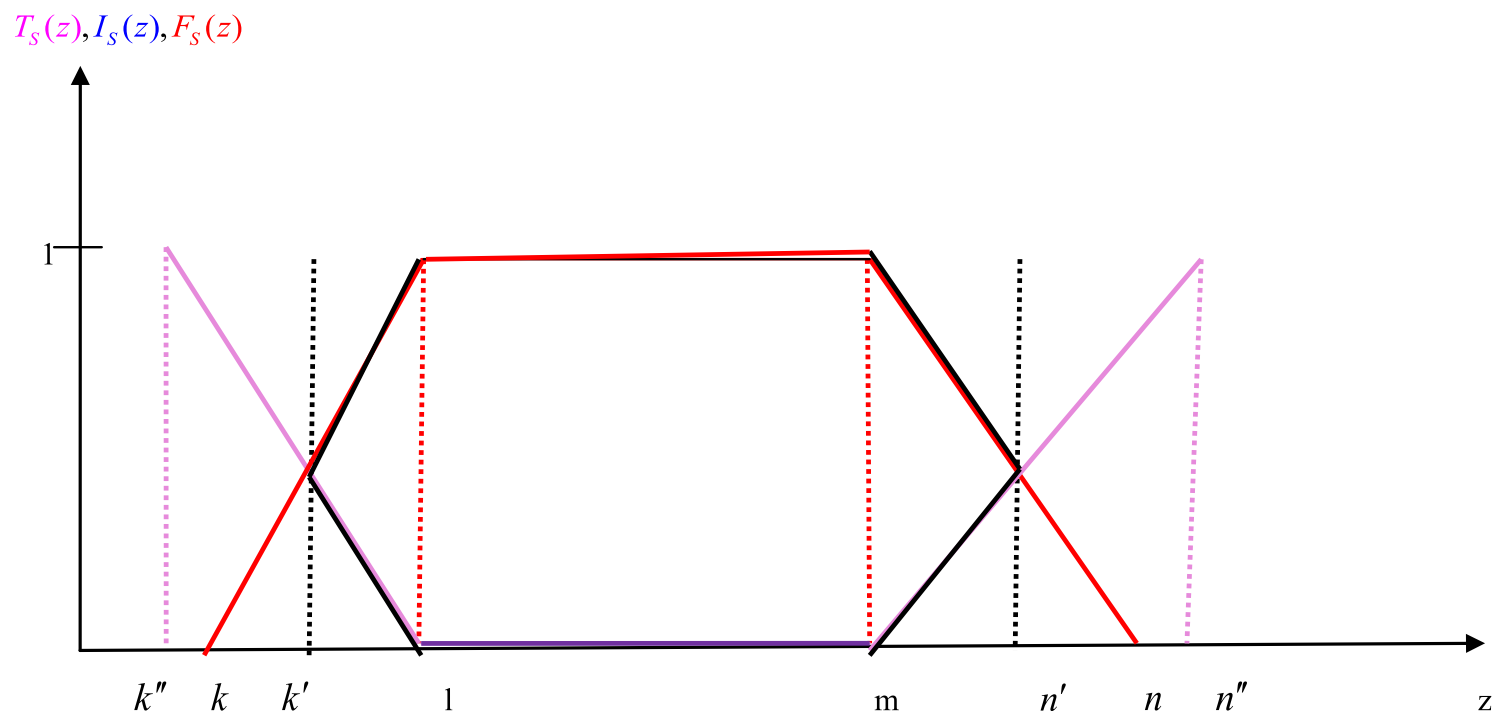

Fig. 1 Truth membership, indeterminacy membership and falsity membership functions of TrNN

Definition 6 [83] Let $g_{1}=\left(\left[k_{1}, l_{1}, m_{1}, n_{1}\right] ; t_{g_{1}}, i_{g_{1}}, f_{g_{1}}\right)$ and $g_{2}=\left(\left[k_{2}, l_{2}, m_{2}, n_{2}\right] ; t_{g_{2}}, i_{g_{2}} f_{g_{2}}\right)$ be any two TrNNs, then the normalized Hamming distance between $g_{1}$ and $g_{2}$ is defined as follows:
Here, $h_{m}^{+}=\max \left\{c_{l m}^{4} \mid l=1,2, \ldots, p\right\}$ and $h_{m}^{-}=$ $\min \left\{b_{l m}^{1} \mid l=1,2, \ldots, p\right\}$ for $m=1,2, \ldots, q$.

Then we obtain the following standardized decision matrix:

$d\left(g_{1}, g_{2}\right)=\frac{1}{12}\left(\begin{array}{r}\left|k_{1}\left(2+t_{g_{1}}-i_{g_{1}}-f_{g_{1}}\right)-k_{2}\left(2+t_{g_{2}}-i_{g_{2}}-f_{g_{2}}\right)\right|+\left|l_{1}\left(2+t_{g_{1}}-i_{g_{1}}-f_{g_{1}}\right)-l_{2}\left(2+t_{g_{2}}-i_{g_{2}}-f_{g_{2}}\right)\right| \\ +\left|m_{1}\left(2+t_{g_{1}}-i_{g_{1}}-f_{g_{1}}\right)-m_{2}\left(2+t_{g_{2}}-i_{g_{2}}-f_{g_{2}}\right)\right|+\left|n_{1}\left(2+t_{g_{1}}-i_{g_{1}}-f_{g_{1}}\right)-n_{2}\left(2+t_{g_{2}}-i_{g_{2}}-f_{g_{2}}\right)\right|\end{array}\right)$.

\section{Standardize the decision matrix}

Assume that $D=\left(c_{l m}\right)_{p \times q}$ is a neutrosophic decision matrix, where $\tilde{c}_{l m}=\left(\left[c_{l m}^{1}, c_{l m}^{2}, c_{l m}^{3}, c_{l m}^{4}\right] ; t_{\tilde{c}_{l m}}, i_{\tilde{c}_{l m}}, f_{\tilde{c}_{l m}}\right)$ is the rating value of alternative $Y_{l}$ with respect to attribute $Z_{m}$. To remove the effects derived from different physical dimensions, the decision matrix $\left(c_{l m}\right)_{p \times q}$ is standardized. We employ the technique [83] to obtain the standardized decision matrix $Z^{*}=\left(\tilde{z}_{l m}\right)_{p \times q}$, in which the component $z_{l m}^{k}$ of the entry $\tilde{z}_{i j}=\left(\left[z_{l m}^{1}, z_{l m}^{2}, z_{l m}^{3}, z_{l m}^{4}\right] ; t_{\tilde{z}_{l m}}, i_{\tilde{z}_{l m}}, f_{\tilde{z}_{l m}}\right)$ in the matrix $S$ is considered as:

1. For benefit type attributes:

$$
\left.\tilde{z}_{l m}=\left(\left[\frac{c_{l m}^{1}}{h_{m}^{+}}, \frac{c_{l m}^{2}}{h_{m}^{+}}, \frac{c_{l m}^{3}}{h_{m}^{+}}, \frac{c_{l m}^{4}}{h_{m}^{+}}\right] ; t_{\tilde{z}_{l m}}, i_{\tilde{z}_{l m}}, f_{\tilde{z}_{l m}}\right)\right\}
$$

2. For cost type attributes:

$$
\tilde{z}_{l m}=\left(\left[\frac{h_{m}^{-}}{c_{l m}^{4}}, \frac{h_{m}^{-}}{c_{l m}^{3}}, \frac{h_{m}^{-}}{c_{l m}^{2}}, \frac{h_{m}^{-}}{c_{l m}^{1}}\right] ; t_{\tilde{z}_{l m}}, i_{\tilde{z}_{l m}}, f_{\bar{z}_{l m}}\right) .
$$

$$
Z^{*}=\left(\tilde{z}_{l m}\right)_{p \times q}=\left(\begin{array}{cccc}
z_{11} & z_{12} & \ldots & z_{1 q} \\
z_{21} & z_{22} & \ldots & z_{2 q} \\
\ldots & \ldots & \ldots & \ldots \\
z_{p 1} & z_{p 2} & \ldots & z_{p q}
\end{array}\right)
$$

\section{TODIM strategy for solving MAGDM problem under TrNN environment}

In this section, we describe the proposed TODIM strategy to solve the MAGDM problem in TrNN environment. In the section process, we propose an MAGDM strategy in TrNN environment. Assume that $u^{\prime}=\left\{u_{1}^{\prime}, u_{2}^{\prime}, \ldots, u_{r}^{\prime}\right\}$ and $v^{\prime}=\left\{v_{1}^{\prime}, v_{2}^{\prime}, \ldots, v_{s}^{\prime}\right\}$ are the alternatives and criteria. Assume that $w^{\prime}=\left\{w_{1}^{\prime}, w_{2}^{\prime}, \ldots, w_{s}^{\prime}\right\}$ is the weight vector of the criteria satisfying $w_{k}^{\prime}>0$ and $\sum_{k=1}^{s} w_{k}^{\prime}=1$. Also assume that $D^{\prime}=\left\{D_{1}^{\prime}, D_{2}^{\prime}, \ldots, D_{h}^{\prime}\right\}$ is the set of $\mathrm{t}$ decision makers and $\lambda^{\prime}=\left\{\lambda_{1}^{\prime}, \lambda_{2}^{\prime}, \ldots, \lambda_{h}^{\prime}\right\}$ is the set of weight vectors of decision makers where $\lambda_{l}^{\prime}>0$ and $\sum_{l=1}^{h} \lambda_{l}^{\prime}=1$.

The proposed TODIM strategy is developed using the following steps (see Fig. 2). 


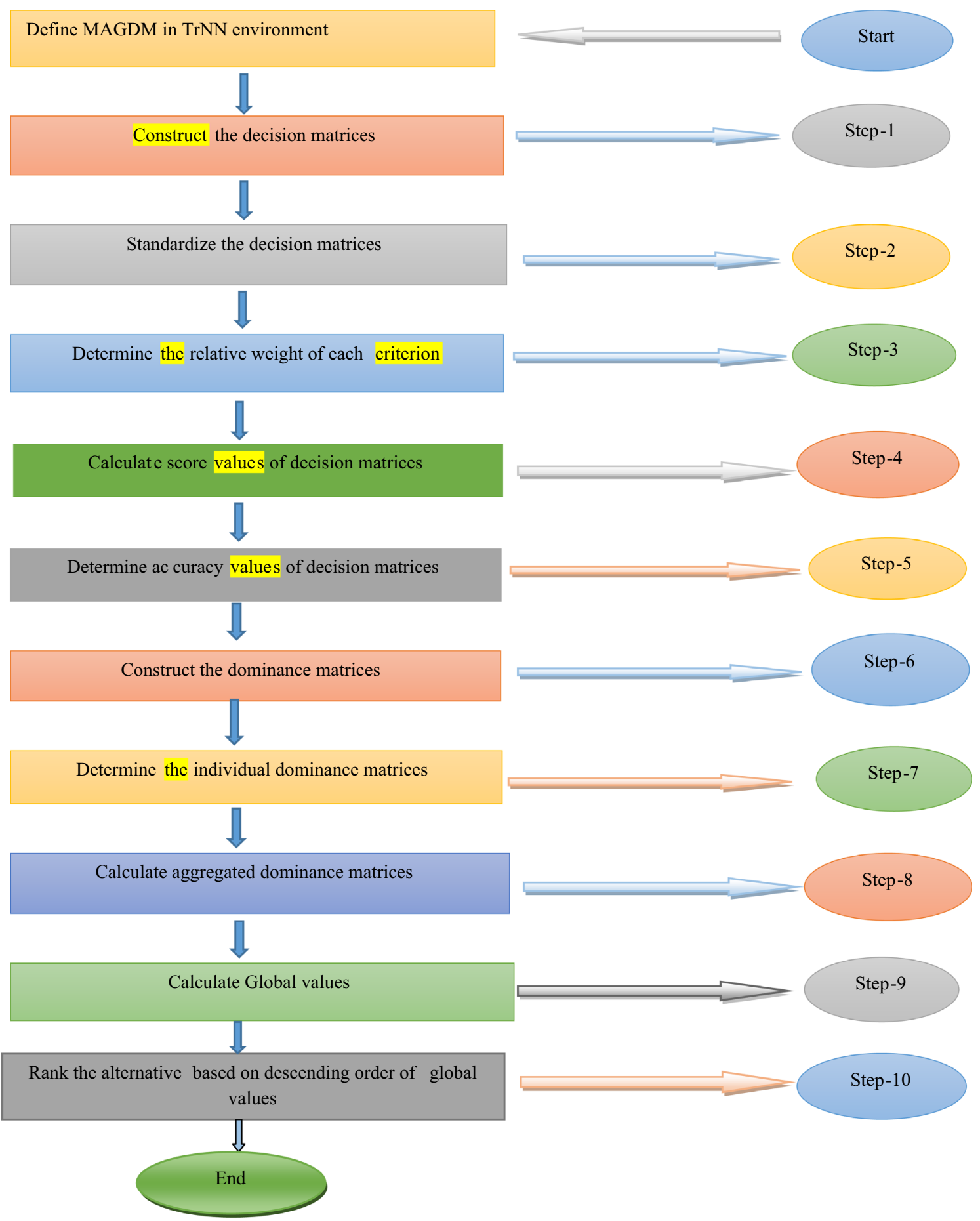

Fig. 2 TODIM strategy in TrNN environment

Step 1: Let $D^{M}=\left(p_{c d}^{M}\right)_{m \times n}$ be the $M$ th decision matrix, where information about the alternative $u_{i}^{\prime}$ is provided by the decision maker $D_{M}$ with respect to attribute $v_{j}^{\prime}(j=$ $1,2, \ldots, s)$. The $M$ th decision matrix denoted by $D^{M}$ is defined as follows:
$D^{M}=\left(\begin{array}{ccccc} & v_{1}^{\prime} & v_{2}^{\prime} & \ldots & v_{s}^{\prime} \\ u_{1}^{\prime} & p_{11}^{M} & p_{12}^{M} & \ldots & p_{1 s}^{M} \\ u_{2}^{\prime} & p_{12}^{M} & p_{22}^{M} & \ldots & p_{2 s}^{M} \\ \ldots & \ldots & \ldots & \ldots & \ldots \\ u_{r}^{\prime} & p_{r 1}^{M} & p_{r 2}^{M} & \ldots & p_{r s}^{M}\end{array}\right)$ 
Here, $M=1,2, \ldots, h ; c=1,2, \ldots, r ; d=1,2, \ldots, s$.

Step 2: To standardize the benefit criteria, we use Eq. (11) and for cost criteria we use (12).

After standardizing, the decision matrix reduces to

$$
D^{M}=\left(\begin{array}{ccccc} 
& v_{1}^{\prime} & v_{2}^{\prime} & \ldots & v_{s}^{\prime} \\
u_{1}^{\prime} & \tilde{p}_{11}^{M} & \tilde{p}_{12}^{M} & \ldots & \tilde{p}_{1 s}^{M} \\
u_{2}^{\prime} & \tilde{p}_{12}^{M} & \tilde{p}_{22}^{M} & \ldots & \tilde{p}_{2 s}^{M} \\
\ldots & \ldots & \ldots & \ldots & \ldots \\
u_{r}^{\prime} & \tilde{p}_{r 1}^{M} & \tilde{p}_{r 2}^{M} & \ldots & \tilde{p}_{r s}^{M}
\end{array}\right) .
$$

Step 3: We calculate relative weight $w_{E C}^{\prime}$ of each criterion by the following equation:

$$
w_{E C}^{\prime}=\frac{w_{E}^{\prime}}{w_{C}^{\prime}} \text {. }
$$

Here, $w_{C}^{\prime}=\max \left\{w_{1}^{\prime}, w_{2}^{\prime}, \ldots, w_{s}^{\prime}\right\}$.

Step 4: Using Eq. (6), we calculate the score value of each alternative w.r.t. each criterion of the decision matrix (14).

Step 5: To calculate the accuracy value of each alternative w.r.t each criterion, we use Eq. (7).

Step 6: We construct the dominance matrix of each alternative $u_{i}^{\prime}$ with respect to the criteria of the $M$ th decision maker $D_{M}$ by the following equation:

$$
\left.\begin{array}{rlr}
\sigma_{c}^{M}\left(p_{i}, p_{j}\right)=\sqrt{\frac{w_{E C}^{\prime}}{\sum_{C=1}^{s} w_{E C}^{\prime}} d\left(\tilde{p}_{i c}^{M}, \tilde{p}_{j c}^{M}\right),} & \text { if } \tilde{p}_{i c}^{M}>\tilde{p}_{j c}^{M} \\
=0, & \text { if } \tilde{p}_{i c}^{M}=\tilde{p}_{j c}^{M} \\
=-\frac{1}{\gamma} \sqrt{\frac{\sum_{C=1}^{s} w_{E C}^{\prime}}{w_{E C}^{\prime}} d\left(\tilde{p}_{i c}^{M}, \tilde{p}_{j c}^{M}\right),} & \text { if } \tilde{p}_{i c}^{M}<\tilde{p}_{j c}^{M}
\end{array}\right\},
$$

where $\gamma$ denotes the decay factor of loss and $\gamma>0$.

Step 7: To obtain the individual final dominance matrix, we use Eq. (17) which is described as:

$\psi_{M}=\sum_{c=1}^{s} \sigma_{c}^{M}\left(p_{i}, p_{j}\right)$

Step 8: We calculate the aggregated dominance matrix by Eq. (18):

$\psi\left(p_{i}, p_{j}\right)=\sum_{M=1}^{t} \lambda_{M} \psi_{M}\left(p_{i}, p_{j}\right)$.
Step 9: To calculate the global value of each alternative, we use Eq. (19):

$$
\tau_{i}=\frac{\sum_{j=1}^{s} \psi\left(p_{i}, p_{j}\right)-\min _{1 \leq i \leq r}\left(\sum_{j=1}^{s} \psi\left(p_{i}, p_{j}\right)\right)}{\max _{1 \leq i \leq r}\left(\sum_{j=1}^{s} \psi\left(p_{i}, p_{j}\right)\right)-\min _{1 \leq i \leq r}\left(\sum_{j=1}^{s} \psi\left(p_{i}, p_{j}\right)\right)} .
$$

Step 10: We rank the global values of the alternatives in descending order. The highest global value is the best alternative.

\section{Illustrative example}

In this section, we demonstrate an example to show the applicability and effectiveness of the proposed strategy. To illustrate the proposed TODIM strategy, we solve an MAGDM problem adapted from [84]. Suppose that an investment company intends to invest a sum of money in the best option. The company constitutes a board of decision makers with three decision makers. The decision makers determine the alternatives to investing money.

The alternatives are:

1. Computer company $\left(u_{1}^{\prime}\right)$.

2. Arms company $\left(u_{2}^{\prime}\right)$.

3. Car company $\left(u_{3}^{\prime}\right)$.

4. Food company $\left(u_{4}^{\prime}\right)$..

The decision makers take the decision based on the following three attributes:

1. Risk factor $\left(v_{1}^{\prime}\right)$.

2. Growth factor $\left(v_{2}^{\prime}\right)$.

3. Environment impact $\left(v_{3}^{\prime}\right)$..

Assume that the weight of attributes and decision makers are $w^{\prime}=(0.3,0.5,0.2)^{\mathrm{T}}$ and $\lambda=(0.36,0.30,0.34)^{\mathrm{T}}$. Now we apply the proposed strategy to solve the problem.

Step 1: Consider the decision matrix in which $u_{1}^{\prime}, u_{2}^{\prime}, u_{3}^{\prime}$ and $u_{4}^{\prime}$ represent the alternatives, and $v_{1}^{\prime}, v_{2}^{\prime}$ and $v_{3}^{\prime}$ represent the criteria. 
Decision matrix for $X_{1}$ :

$M^{1}=\left(\begin{array}{cccc}v_{1}^{\prime} & v_{2}^{\prime} & v_{3}^{\prime} \\ u_{1}^{\prime}([0.4,0.5,0.5,0.6] ; 0.3,0.1,0.2) & ([0.3,0.4,0.5,0.5] ; 0.4,0.2,0.3) & ([0.2,0.3,0.4,0.5] ; 0.3,0.3,0.2) \\ u_{2}^{\prime}([0.3,0.3,0.4,0.4] ; 0.5,0.3,0.4) & ([0.2,0.3,0.3,0.3] ; 0.5,0.2,0.5) & ([0.4,0.5,0.6,0.6] ; 0.4,0.2,0.3) \\ u_{3}^{\prime}([0.4,0.4,0.5,0.6] ; 0.4,0.3,0.3) & ([0.3,0.4,0.5,0.6] ; 0.3,0.4,0.2) & ([0.1,0.2,0.2,0.3] ; 0.3,0.2,0.1) \\ u_{4}^{\prime}([0.3,0.4,0.5,0.5] ; 0.2,0.3,0.1) & ([0.2,0.3,0.3,0.6] ; 0.5,0.2,0.2) & ([0.3,0.4,0.7,0.7] ; 0.5,0.4,0.3)\end{array}\right)$.

Decision matrix for $X_{2}$ :

$M^{2}=\left(\begin{array}{ccc}v_{1}^{\prime} & v_{2}^{\prime} & v_{3}^{\prime} \\ u_{1}^{\prime}([0.6,0.7,0.7,0.8] ; 0.3,0.4,0.1) & ([0.5,0.6,0.6,0.7] ; 0.5,0.4,0.3) & ([0.3,0.5,0.6,0.7] ; 0.5,0.4,0.2) \\ u_{2}^{\prime}([0.5,0.6,0.7,0.7] ; 0.5,0.3,0.4) & ([0.2,0.3,0.5,0.5] ; 0.4,0.5,0.3) & ([0.4,0.5,0.6,0.7] ; 0.4,0.2,0.3) \\ u_{3}^{\prime}([0.4,0.5,0.6,0.6] ; 0.8,0.3,0.4) & ([0.3,0.4,0.5,0.5] ; 0.3,0.4,0.5) & ([0.6,0.6,0.7,0.7] ; 0.2,0.3,0.1) \\ u_{4}^{\prime}([0.3,0.5,0.6,0.7] ; 0.7,0.4,0.5) & ([0.4,0.5,0.6,0.6] ; 0.4,0.4,0.3) & ([0.5,0.6,0.7,0.8] ; 0.5,0.1,0.2)\end{array}\right)$.

Decision matrix for $X_{3}$ :

$M^{3}=\left(\begin{array}{ccc}v_{1}^{\prime} & v_{2}^{\prime} & v_{3}^{\prime} \\ u_{1}^{\prime}([0.4,0.5,0.6,0.6] ; 0.3,0.2,0.2) & ([0.4,0.5,0.5,0.5] ; 0.3,0.5,0.2) & ([0.2,0.3,0.4,0.4] ; 0.4,0.3,0.3) \\ u_{2}^{\prime}([0.5,0.6,0.6,0.7] ; 0.4,0.5,0.6) & ([0.3,0.5,0.5,0.6] ; 0.8,0.2,0.3) & ([0.3,0.4,0.4,0.5] ; 0.5,0.3,0.2) \\ u_{3}^{\prime}([0.6,0.7,0.7,0.8] ; 0.4,0.3,0.3) & ([0.6,0.6,0.6,0.7] ; 0.6,0.5,0.4) & ([0.4,0.5,0.6,0.6] ; 0.4,0.2,0.2) \\ u_{4}^{\prime}([0.5,0.5,0.7,0.7] ; 0.2,0.1,0.1) & ([0.5,0.5,0.6,0.8] ; 0.3,0.2,0.2) & ([0.3,0.5,0.5,0.7] ; 0.5,0.2,0.3)\end{array}\right)$.

Step 2: Since all the criteria are of the benefit type, we do not need to standardize the decision matrix.

Step 3: In this step, we obtain the relative weight for each criteria using Eq. (15) as

$w_{E C_{1}}^{\prime}=0.6, \quad w_{E C_{2}}^{\prime}=1, \quad w_{E C_{3}}^{\prime}=0.4$

Step 4: Using Eq. (6), we obtain the score value of each alternative with respect to each criterion. The score values are presented in matrix form as shown (see matrix 1, matrix 2 and matrix 3).

Matrix 1: Score value for $M^{1}$

$$
\left(\begin{array}{cccc} 
& v_{1}^{\prime} & v_{2}^{\prime} & v_{3}^{\prime} \\
u_{1}^{\prime} & 0.33 & 0.27 & 0.21 \\
u_{2}^{\prime} & 0.21 & 0.16 & 0.33 \\
u_{3}^{\prime} & 0.28 & 0.25 & 0.13 \\
u_{4}^{\prime} & 0.25 & 0.26 & 0.31
\end{array}\right)
$$

Matrix 2: Score value for $M^{2}$

$$
\left(\begin{array}{cccc} 
& v_{1}^{\prime} & v_{2}^{\prime} & v_{3}^{\prime} \\
u_{1}^{\prime} & 0.42 & 0.36 & 0.33 \\
u_{2}^{\prime} & 0.37 & 0.2 & 0.35 \\
u_{3}^{\prime} & 0.36 & 0.2 & 0.39 \\
u_{4}^{\prime} & 0.31 & 0.3 & 0.48
\end{array}\right)
$$

Matrix 3: Score value for $M^{3}$

$$
\left(\begin{array}{cccc} 
& v_{1}^{\prime} & v_{2}^{\prime} & v_{3}^{\prime} \\
u_{1}^{\prime} & 0.33 & 0.25 & 0.19 \\
u_{2}^{\prime} & 0.26 & 0.36 & 0.27 \\
u_{3}^{\prime} & 0.42 & 0.35 & 0.35 \\
u_{4}^{\prime} & 0.4 & 0.38 & 0.33
\end{array}\right)
$$

Step 5: In this step, we calculate the accuracy function using Eq. (7).

Matrix 4: Accuracy value for $M^{1}$

$$
\left(\begin{array}{cccc} 
& v_{1}^{\prime} & v_{2}^{\prime} & v_{3}^{\prime} \\
u_{1}^{\prime} & 0.05 & 0.04 & 0.04 \\
u_{2}^{\prime} & 0.03 & 0 & 0.05 \\
u_{3}^{\prime} & 0.05 & 0.04 & 0.04 \\
u_{4}^{\prime} & 0.04 & 0.11 & 0.10
\end{array}\right) .
$$

Matrix 5: Accuracy value for $M^{2}$

$$
\left(\begin{array}{cccc} 
& v_{1}^{\prime} & v_{2}^{\prime} & v_{3}^{\prime} \\
u_{1}^{\prime} & 0.14 & 0.12 & 0.19 \\
u_{2}^{\prime} & 0.06 & 0.03 & 0.06 \\
u_{3}^{\prime} & 0.21 & 0.08 & 0.06 \\
u_{4}^{\prime} & 0.12 & 0.05 & 0.20
\end{array}\right) .
$$


Matrix 6: Accuracy value for $M^{3}$

$\left(\begin{array}{cccc} & v_{1}^{\prime} & v_{2}^{\prime} & v_{3}^{\prime} \\ u_{1}^{\prime} & 0.05 & 0.05 & 0.03 \\ u_{2}^{\prime} & 0.12 & 0.23 & 0.12 \\ u_{3}^{\prime} & 0.07 & 0.13 & 0.10 \\ u_{4}^{\prime} & 0.06 & 0.06 & 0.10\end{array}\right)$

Step 6: Using Eq. (16), we calculate the dominance matrix (taking $\gamma=1$ ) (matrices 7-15).

Matrix 7: Dominance matrix $\sigma_{1}^{1}$

$\sigma_{1}^{1}=\left(\begin{array}{ccccc} & u_{1}^{\prime} & u_{2}^{\prime} & u_{3}^{\prime} & u_{4}^{\prime} \\ u_{1}^{\prime} & 0 & 0.1923 & 0.1204 & 0.1533 \\ u_{2}^{\prime} & -0.6411 & 0 & -0.5109 & -0.3873 \\ u_{3}^{\prime} & -0.4012 & 0.1517 & 0 & 0.0949 \\ u_{4}^{\prime} & -0.5056 & 0.1162 & -0.3162 & 0\end{array}\right)$.

Matrix 8: Dominance matrix $\sigma_{2}^{1}$

$\sigma_{2}^{1}=\left(\begin{array}{ccccc} & u_{1}^{\prime} & u_{2}^{\prime} & u_{3}^{\prime} & u_{4}^{\prime} \\ u_{1}^{\prime} & 0 & 0.2282 & 0.2135 & 0.1947 \\ u_{2}^{\prime} & -0.4565 & 0 & -0.2768 & -0.4 \\ u_{3}^{\prime} & -0.1959 & 0.1384 & 0 & -0.4082 \\ u_{4}^{\prime} & -0.3896 & 0.2 & 0.1549 & 0\end{array}\right)$.

Matrix 9: Dominance matrix $\sigma_{3}^{1}$

$\sigma_{3}^{1}=\left(\begin{array}{ccccc} & u_{1}^{\prime} & u_{2}^{\prime} & u_{3}^{\prime} & u_{4}^{\prime} \\ u_{1}^{\prime} & 0 & -0.7826 & 0.1238 & -0.7246 \\ u_{2}^{\prime} & 0.1565 & 0 & 0.1996 & 0.1072 \\ u_{3}^{\prime} & -0.6192 & -0.9980 & 0 & -0.9531 \\ u_{4}^{\prime} & 0.1449 & -0.5362 & 0.1906 & 0\end{array}\right)$.

Matrix 10: Dominance matrix $\sigma_{1}^{2}$

$$
\sigma_{1}^{2}=\left(\begin{array}{ccccc} 
& u_{1}^{\prime} & u_{2}^{\prime} & u_{3}^{\prime} & u_{4}^{\prime} \\
u_{1}^{\prime} & 0 & 0.1162 & 0.1255 & 0.1884 \\
u_{2}^{\prime} & -0.3873 & 0 & 0.0474 & 0.1360 \\
u_{3}^{\prime} & -0.4183 & -0.1581 & 0 & 0.1254 \\
u_{4}^{\prime} & -0.6279 & -0.4535 & -0.4183 & 0
\end{array}\right)
$$

Matrix 11: Dominance matrix $\sigma_{2}^{2}$

$$
\sigma_{2}^{2}=\left(\begin{array}{ccccc} 
& u_{1}^{\prime} & u_{2}^{\prime} & u_{3}^{\prime} & u_{4}^{\prime} \\
u_{1}^{\prime} & 0 & 0.2828 & 0.2843 & 0.1768 \\
u_{2}^{\prime} & -0.5657 & 0 & -0.2517 & -0.4416 \\
u_{3}^{\prime} & -0.5687 & 0.1258 & 0 & -0.4454 \\
u_{4}^{\prime} & -0.3535 & 0.2208 & 0.2227 & 0
\end{array}\right)
$$

Matrix 12: Dominance matrix $\sigma_{3}^{2}$

$$
\sigma_{3}^{2}=\left(\begin{array}{ccccc} 
& u_{1}^{\prime} & u_{2}^{\prime} & u_{3}^{\prime} & u_{4}^{\prime} \\
u_{1}^{\prime} & 0 & -0.2811 & -0.5882 & -0.8491 \\
u_{2}^{\prime} & 0.0562 & 0 & -0.5162 & -0.8009 \\
u_{3}^{\prime} & 0.1176 & 0.1032 & 0 & -0.6584 \\
u_{4}^{\prime} & 0.1698 & 0.1602 & 0.1317 & 0
\end{array}\right)
$$

Matrix 13: Dominance matrix $\sigma_{1}^{3}$

$$
\sigma_{1}^{3}=\left(\begin{array}{ccccc} 
& u_{1}^{\prime} & u_{2}^{\prime} & u_{3}^{\prime} & u_{4}^{\prime} \\
u_{1}^{\prime} & 0 & 0.1475 & -0.5401 & -0.4564 \\
u_{2}^{\prime} & -0.4915 & 0 & -0.7303 & -0.6831 \\
u_{3}^{\prime} & 0.1620 & 0.2191 & 0 & 0.1760 \\
u_{4}^{\prime} & 0.1423 & 0.2049 & -0.5868 & 0
\end{array}\right) \text {. }
$$

Matrix 14: Dominance matrix $\sigma_{2}^{3}$

$$
\sigma_{2}^{3}=\left(\begin{array}{ccccc} 
& u_{1}^{\prime} & u_{2}^{\prime} & u_{3}^{\prime} & u_{4}^{\prime} \\
u_{1}^{\prime} & 0 & -0.4707 & -0.4490 & -0.5034 \\
u_{2}^{\prime} & 0.2354 & 0 & 0.1809 & -0.3187 \\
u_{3}^{\prime} & 0.2245 & -0.3605 & 0 & -0.3137 \\
u_{4}^{\prime} & 0.2517 & 0.1594 & 0.1568 & 0
\end{array}\right)
$$

Matrix 15: Dominance matrix $\sigma_{3}^{3}$

$$
\sigma_{3}^{3}=\left(\begin{array}{ccccc} 
& u_{1}^{\prime} & u_{2}^{\prime} & u_{3}^{\prime} & u_{4}^{\prime} \\
u_{1}^{\prime} & 0 & -0.5987 & -0.8803 & -0.8316 \\
u_{2}^{\prime} & 0.1197 & 0 & -0.6454 & -0.5775 \\
u_{3}^{\prime} & 0.1761 & 0.1291 & 0 & 0.1 \\
u_{4}^{\prime} & 0.1663 & 0.1155 & -0.5 & 0
\end{array}\right)
$$

Step 7: Using Eq. (17), we constructed the final dominance matrix (matrices 16-18).

Matrix 16: Final dominance matrix $\psi_{1}$

$$
\Psi_{1}=\left(\begin{array}{ccccc} 
& u_{1}^{\prime} & u_{2}^{\prime} & u_{3}^{\prime} & u_{4}^{\prime} \\
u_{1}^{\prime} & 0 & -0.3621 & 0.4577 & -0.3766 \\
u_{2}^{\prime} & -0.9411 & 0 & -0.6681 & -0.6801 \\
u_{3}^{\prime} & -1.2163 & -0.7079 & 0 & -1.2664 \\
u_{4}^{\prime} & -0.7503 & -0.22 & 0.0293 & 0
\end{array}\right) .
$$

Matrix 17: Final dominance matrix $\psi_{2}$

$\psi_{2}=\left(\begin{array}{ccccc} & u_{1}^{\prime} & u_{2}^{\prime} & u_{3}^{\prime} & u_{4}^{\prime} \\ u_{1}^{\prime} & 0 & 0.1179 & -0.1784 & -0.4839 \\ u_{2}^{\prime} & -0.8968 & 0 & -0.7205 & -1.1065 \\ u_{3}^{\prime} & -0.8694 & 0.0709 & 0 & -0.9784 \\ u_{4}^{\prime} & -0.8116 & -0.0725 & -0.0639 & 0\end{array}\right)$ 
Table 1 Ranking order of alternatives for different values of parameter $\gamma$

\begin{tabular}{lll}
\hline Value of $\gamma$ & Global value & Ranking order of the alternatives \\
\hline$\gamma=1$ & $\tau_{1}=0.3952, \tau_{2}=0, \tau_{3}=0.6611, \tau_{4}=1$ & $u_{4}^{\prime}>u_{3}^{\prime}>u_{1}^{\prime}>u_{2}^{\prime}$ \\
$\gamma=2$ & $\tau_{1}=0.4689, \tau_{2}=0, \tau_{3}=0.2904, \tau_{4}=1$ & $u_{4}^{\prime}>u_{1}^{\prime}>u_{3}^{\prime}>u_{2}^{\prime}$ \\
$\gamma=3$ & $\tau_{1}=0.5243, \tau_{2}=0, \tau_{3}=0.3248, \tau_{4}=1$ & $u_{4}^{\prime}>u_{1}^{\prime}>u_{3}^{\prime}>u_{2}^{\prime}$ \\
$\gamma=4$ & $\tau_{1}=0.5267, \tau_{2}=0, \tau_{3}=0.4842, \tau_{4}=1$ & $u_{4}^{\prime}>u_{1}^{\prime}>u_{3}^{\prime}>u_{2}^{\prime}$ \\
$\gamma=5$ & $\tau_{1}=0.5591, \tau_{2}=0, \tau_{3}=0.5702, \tau_{4}=1$ & $u_{4}^{\prime}>u_{3}^{\prime}>u_{1}^{\prime}>u_{2}^{\prime}$ \\
\hline
\end{tabular}

Matrix 18: Final dominance matrix $\psi_{3}$

$$
\psi_{3}=\left(\begin{array}{ccccc} 
& u_{1}^{\prime} & u_{2}^{\prime} & u_{3}^{\prime} & u_{4}^{\prime} \\
u_{1}^{\prime} & 0 & -0.9219 & -1.8694 & -1.7914 \\
u_{2}^{\prime} & -.1364 & 0 & -1.1948 & -1.5793 \\
u_{3}^{\prime} & 0.5626 & -0.0123 & 0 & 0.0377 \\
u_{4}^{\prime} & 0.5603 & 0.4798 & -0.93 & 0
\end{array}\right) .
$$

Step 8: Using Eq. (18), we construct the aggregated dominance matrix.

Matrix 19: Aggregated dominance matrix

$$
\psi=\left(\begin{array}{ccccc} 
& u_{1}^{\prime} & u_{2}^{\prime} & u_{3}^{\prime} & u_{4}^{\prime} \\
u_{1}^{\prime} & 0 & -0.4084 & -0.5243 & -0.8898 \\
u_{2}^{\prime} & -0.6542 & 0 & -0.8629 & -1.1137 \\
u_{3}^{\prime} & -0.5074 & -0.2378 & 0 & -0.5327 \\
u_{4}^{\prime} & -0.3231 & 0.0622 & -0.3248 & 0
\end{array}\right) .
$$

Step 9: Using Eq. (19), we calculate the global value $\tau_{i}$

$\tau_{1}=0.3952, \quad \tau_{2}=0, \quad \tau_{3}=0.6611, \quad \tau_{4}=1$.

\section{Step 10: Since}

$\tau_{4}>\tau_{3}>\tau_{1}>\tau_{2}$

the ranking order of the alternatives is

$u_{4}^{\prime}>u_{3}^{\prime}>u_{1}^{\prime}>u_{2}^{\prime}$

Thus, we see that the food company is the best option to invest in.

\section{Sensitive analysis on influence of the parameter $\gamma$ to ranking order}

We see that for different values of $\gamma$, we obtain different global values that affect the ranking order of the alternatives. When $\gamma=1,2,3,4,5$, the ranking order of the alternatives are presented in Table 1 . When $\gamma=1,2,3,4$, and 5, $u_{4}^{\prime}$ is the best alternative and $u_{2}^{\prime}$ is the worst alternative. Also we see that for $\gamma=2, \gamma=3$, and $\gamma=4$, the ranking order of the alternatives remains the same as $u_{4}^{\prime}>u_{1}^{\prime}>u_{3}^{\prime}>u_{2}^{\prime}$. For $\gamma=1$, and $\gamma=$ 5 , we obtain the ranking order as $u_{4}^{\prime}>u_{3}^{\prime}>u_{1}^{\prime}>u_{2}^{\prime}$. So we obtain two different ranking orders, but the best alternative remains the same as the food company $\left(u_{4}^{\prime}\right)$ and the worst alternative is the arms company $\left(u_{2}^{\prime}\right)$. Therefore, we can say that the ranking order of the alternatives depends on the decay factor of loss $\gamma$.

\section{Conclusion}

We have developed a trapezoidal neutrosophic multiple attribute group decision-making strategy, namely TODIM strategy, in which the evaluation values of alternatives over the attributes assume the form of trapezoidal neutrosophic numbers.

The advantage of the proposed strategy is that it is more suitable for solving multiple attribute group decision-making problems with trapezoidal neutrosophic information because trapezoidal neutrosophic numbers can handle indeterminate and inconsistent information and are the extension of trapezoidal intuitionistic fuzzy numbers.

We also illustrate the developed TODIM strategy by solving a numerical example of the investment problem. We hope that the proposed TODIM strategy can be applied to solve real-world decision-making problems such as brick selection [92, 93], teacher selection [94] and weaver selection [95].

Open Access This article is distributed under the terms of the Creative Commons Attribution 4.0 International License (http://creativecomm ons.org/licenses/by/4.0/), which permits unrestricted use, distribution, and reproduction in any medium, provided you give appropriate credit to the original author(s) and the source, provide a link to the Creative Commons license, and indicate if changes were made.

\section{References}

1. Smarandache F (1998) A unifying field in logics. Neutrosophy: neutrosophic probability, set and logic. American Research Press, Rehoboth

2. Wang H, Smarandache F, Sunderraman R, Zhang Y, Sunderraman1 R (2010) Single valued neutrosophic sets. Rev Air Force Acad 1(16):10-14. http://213.177.9.66/ro/revista/NR_1_ 2010/Art_Smarandache.pdf. Accessed 2 Jan 2019

3. Biswas P, Pramanik S, Giri BC (2014) A new methodology for neutrosophic multi-attribute decision making with unknown weight 
information. Neutrosophic Sets Syst 3:42-52. https://doi.org/10. 5281/zenodo.571212

4. Biswas P, Pramanik S, Giri BC (2015) TOPSIS method for multiattribute group decision making under single-valued neutrosophic environment. Neural Comput Appl 27(3):727-737. https://doi.org/ 10.1007/s00521-015-1891-2

5. Mondal K, Pramanik S (2015) Neutrosophic tangent similarity measure and its application to multiple attribute decision making. Neutrosophic Sets Syst 9:80-87. https://doi.org/10.5281/zenodo. 571578

6. Pramanik S, Dalapati S, Roy TK (2016) Logistics center location selection approach based on neutrosophic multi-criteria decision making. In: Smarandache F, Pramanik S (eds) New trends in neutrosophic theory and applications. Pons Editions, Brussels, pp 161-174

7. Smarandache F, Pramanik S (eds) (2016) New trends in neutrosophic theory and applications. Pons Editions, Brussels

8. Biswas P, Pramanik S, Giri BC (2017) Hybrid vector similarity measures and their applications to multi-attribute decision making under neutrosophic environment. Neural Comput Appl 28(5):1163-1176. https://doi.org/10.1007/s00521-015-2125-3

9. Pramanik S, Mallick R, Dasgupta A (2018) Contributions of selected Indian researchers to multi-attribute decision making in neutrosophic environment. Neutrosophic Sets Syst 20:108-131. https://doi.org/10.5281/zenodo.1284870

10. Mondal K, Pramanik S, Giri BC (2018) Single valued neutrosophic hyperbolic sine similarity measure based MADM strategy. Neutrosophic Sets Syst 20:3-11. https://doi.org/10.5281/zenodo.1235383

11. Mondal K, Pramanik S, Giri BC (2018) Hybrid binary logarithm similarity measure for MAGDM problems under SVNS assessments. Neutrosophic Sets Syst 20:12-25. https://doi.org/10.5281/ zenodo. 1235365

12. Ji P, Wang JQ, Zhang HY (2016) Frank prioritized Bonferroni mean operator with single-valued neutrosophic sets and its application in selecting third-party logistics providers. Neural Comput Appl 30(3):799-823. https://doi.org/10.1007/s00521-016-2660-6

13. Kharal A (2014) A neutrosophic multi-criteria decision making method. New Math Nat Comput 10:143-162. https://doi.org/10. 1142/S1793005714500070

14. Liu P, Chu Y, Li Y, Chen Y (2014) Some generalized neutrosophic number Hamacher aggregation operators and their application to group decision making. Int J Fuzzy Syst 16(2):242-255

15. Liu PD, Li HG (2017) Multiple attribute decision-making method based on some normal neutrosophic Bonferroni mean operators. Neural Comput Appl 28:179-194. https://doi.org/10.1007/s00521015-2048-Z

16. Liu P, Wang Y (2014) Multiple attribute decision-making method based on single-valued neutrosophic normalized weighted Bonferroni mean. Neural Comput Appl 25(7):2001-2010. https://doi.org/ $10.1007 / \mathrm{s} 00521-014-1688-8$

17. Sahin R, Kucuk A (2014) Subsethood measure for single valued neutrosophic sets. J Intell Fuzzy Syst 29(3):525-530. https://doi. org/10.3233/IFS-141304

18. Biswas P, Pramanik S, Giri BC (2018) Neutrosophic TOPSIS with group decision making. In: Kahraman C, Otay I (eds) Fuzzy multicriteria decision making using neutrosophic sets. Studies in fuzziness and soft computing. Springer, Cham, pp 543-585. https:// doi.org/10.1007/978-3-030-00045-5_21

19. Ye J (2013) Multicriteria decision-making method using the correlation coefficient under single-valued neutrosophic environment. Int J Gen Syst 42:386-394. https://doi.org/10.1080/03081079. 2012.761609

20. Abdel-Basset M, Manogaran G, Gamal A et al (2018) A hybrid approach of neutrosophic sets and DEMATEL method for developing supplier selection criteria. Des Autom Embed Syst 22(3):257-287. https://doi.org/10.1007/s10617-018-9203-6
21. Abdel-Basset M, Mohamed M, Zhou Y et al (2017) Multi-criteria group decision making based on neutrosophic analytic hierarchy process. J Intell Fuzzy Syst 33(6):4055-4066. https://doi.org/10. 3233/JIFS-17981

22. Abdel-Basset M, Mohamed M, Smarandache F (2018) An extension of neutrosophic AHP-SWOT analysis for strategic planning and decision-making. Symmetry 10:116. https://doi.org/10.3390/ sym10040116

23. Abdel-Basset M, Gunasekaran M, Mohamed M, Chilamkurti NK (2018) Three-way decisions based on neutrosophic sets and AHPQFD framework for supplier selection problem. Future Gener Comput Syst. https://doi.org/10.1016/j.future.2018.06.024

24. Abdel-Basset M, Mohamed M, Smarandache F (2018) A hybrid neutrosophic group ANP-TOPSIS framework for supplier selection problems. Symmetry 10(6):226. https://doi.org/10.3390/ sym 10060226

25. Abdel-Basset M, Zhou Y, Mohamed M et al (2018) A group decision making framework based on neutrosophic VIKOR approach for e-government website evaluation. J Intell Fuzzy Syst 34(6):4213-4224. https://doi.org/10.3233/JIFS-171952

26. Abdel-Basset M, Mohamed M (2018) The role of single valued neutrosophic sets and rough sets in smart city: imperfect and incomplete information systems. Measurement 124:47-55. https://doi. org/10.1016/j.measurement.2018.04.001

27. Sahin M, Olgun N, Ulucay V, Kargin A, Smarandache F (2017) A new similarity measure based on falsity value between single valued neutrosophic sets based on the centroid points of transformed single valued neutrosophic number with applications to pattern recognition. Neutrosophic Sets Syst 15:31-48. https://doi. org/10.5281/zenodo.570934

28. Sahin M, Ulucay V, Acioglu H (2018) Some weighted arithmetic operator and geometric operators with SVNSs and their application to multi-criteria decision making problem. New trends in neutrosophic theory and applications, vol II. Pons Editions, Brussels, pp 85-104

29. Abdel-Basset M, Mohamed M, Sangaiah AK, Jain V (2018) An integrated neutrosophic AHP and SWOT method for strategic planning methodology selection. Benchmarking Int J 25(7):2546-2564. https://doi.org/10.1108/BIJ-08-2017-0232

30. Pramanik S, Dey PP, Giri BC (2015) An extended grey relational analysis based interval neutrosophic multi-attribute decision making for weaver selection. J New Theory 9:82-93

31. Dey PP, Pramanik S, Giri BC (2016) Extended projection based models for solving multiple attribute decision making problems with interval valued neutrosophic information. In: Smarandache F, Pramanik S (eds) New trends in neutrosophic theory and applications. Pons Editions, Brussels, pp 127-140

32. Dalapati S, Pramanik S, Alam S, Smarandache F, Roy TK (2017) IN-cross entropy based MAGDM strategy under interval neutrosophic set environment. Neutrosophic Sets Syst 18:43-57. https:// doi.org/10.5281/zenodo.1175162

33. Mondal K, Pramanik S, Giri BC (2018) Interval neutrosophic tangent similarity measure based MADM strategy and its application to MADM problems. Neutrosophic Sets Syst 19:47-56. https://doi. org/10.5281/zenodo.1235201

34. Pramanik S, Dey PP, Giri BC (2015) TOPSIS for single valued neutrosophic soft expert set based multi-attribute decision making problems. Neutrosophic Sets Syst 10:88-95. https://doi.org/ 10.5281/zenodo. 571238

35. Pramanik S, Dey PP, Giri BC (2016) Neutrosophic soft multiattribute decision making based on grey relational projection method. Neutrosophic Sets Syst 11:98-106. https://doi.org/10. 5281/zenodo.571576

36. Pramanik S, Dey PP, Giri BC (2016) Neutrosophic soft multiattribute group decision making based on grey relational analysis

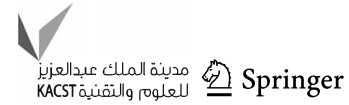


method. J New Results Sci 10:25-37. https://doi.org/10.5281/ zenodo.34869

37. Pramanik S, Dalapati S (2016) GRA based multi criteria decision making in generalized neutrosophic soft set environment. Glob J Eng Sci Res Manag 3(5):153-169. https://doi.org/10.5281/zenodo. 53753

38. Ulucay V, Sahin M, Olgun N (2018) Time-neutrosophic soft expert sets and its decision making problem. Matematika 34(2):246-260. https://doi.org/10.11113/matematika.v34.n2.934

39. Ulucay V, Sahin M, Hassan N (2018) Generalized neutrosophic soft expert set for multi-criteria decision making. Symmetry 10(10):437. https://doi.org/10.3390/sym10100437

40. Bakbak D, Ulucay V, Sahin M (2019) Neutrosophic soft expert multiset and their application to multiple criteria decision making. Mathematics 7(1):50. https://doi.org/10.3390/math7010050

41. Mondal K, Pramanik S (2015) Rough neutrosophic multi-attribute decision-making based on grey relational analysis. Neutrosophic Sets Syst 7:8-17. https://doi.org/10.5281/zenodo.571603

42. Mondal K, Pramanik S (2015) Rough neutrosophic multi-attribute decision-making based on rough accuracy score function. Neutrosophic Sets Syst 8:14-21. https://doi.org/10.5281/zenodo.571604

43. Mondal K, Pramanik S (2015) Tri-complex rough neutrosophic similarity measure and its application in multi-attribute decision making. Crit Rev 11:26-40

44. Mondal K, Pramanik S, Smarandache F (2016) Rough neutrosophic TOPSIS for multi-attribute group decision making. Neutrosophic Sets Syst 13:105-117. https://doi.org/10.5281/zenodo.570866

45. Mondal K, Pramanik S, Smarandache F (2016) Multi-attribute decision making based on rough neutrosophic variational coefficient similarity measure. Neutrosophic Sets Syst 13:3-17. https:// doi.org/10.5281/zenodo.570854

46. Mondal K, Pramanik S, Smarandache F (2016) Rough neutrosophic hyper-complex set and its application to multiattribute decision making. Crit Rev 13:111-126

47. Pramanik S, Roy R, Roy TK, Smarandache F (2017) Multi criteria decision making using correlation coefficient under rough neutrosophic environment. Neutrosophic Sets Syst 17:29-36. https://doi. org/10.5281/zenodo.1012237

48. Pramanik S, Roy R, Roy TK (2018) Multi criteria decision making based on projection and bidirectional projection measures of rough neutrosophic sets. In: Smarandache F, Pramanik S (eds) New trends in neutrosophic theory and applications, vol 2. Pons Editions, Brussels, pp 175-187

49. Mondal K, Pramanik S (2015) Decision making based on some similarity measures under interval rough neutrosophic environment. Neutrosophic Sets Syst 10:46-57. https://doi.org/10.5281/zenodo. 571358

50. Pramanik S, Roy R, Roy TK, Smarandache F (2018) Multi attribute decision making strategy on projection and bidirectional projection measures of interval rough neutrosophic sets. Neutrosophic Sets Syst 19:101-109. https://doi.org/10.5281/zenodo.1235211

51. Pramanik S, Roy R, Roy TK, Smarandache F (2018) Multiattribute decision making based on several trigonometric Hamming similarity measures under interval rough neutrosophic environment. Neutrosophic Sets Syst 19:110-118. https://doi.org/10.5281/ zenodo. 1235207

52. Mondal K, Pramanik S (2015) Neutrosophic refined similarity measure based on tangent function and its application to multi attribute decision making. J New Theory 8:41-50. https://doi.org/10.5281/ zenodo. 23176

53. Mondal K, Pramanik S (2015) Neutrosophic refined similarity measure based on cotangent function and its application to multiattribute decision making. Glob J Adv Res 2(2):486-494

54. Mondal K, Pramanik S, Giri BC (2018) Multi-criteria group decision making based on linguistic refined neutrosophic strategy. In:
Smarandache F, Pramanik S (eds) New trends in neutrosophic theory and applications, vol 2. Pons Editions, Brussels, pp 125-139

55. Biswas P, Pramanik S, Giri BC (2016) Some distance measures of single valued neutrosophic hesitant fuzzy sets and their applications to multiple attribute decision making. In: Smarandache F, Pramanik $\mathrm{S}$ (eds) New trends in neutrosophic theory and applications. Pons Editions, Brussels, pp 55-63

56. Biswas P, Pramanik S, Giri BC (2016) GRA method of multiple attribute decision making with single valued neutrosophic hesitant fuzzy set information. In: Smarandache F, Pramanik S (eds) New trends in neutrosophic theory and applications. Pons Editions, Brussels, pp 55-63

57. Dey PP, Pramanik S, Giri BC (2016) TOPSIS for solving multiattribute decision making problems under bi-polar neutrosophic environment. In: Smarandache F, Pramanik S (eds) New trends in neutrosophic theory and applications. Pons Editions, Brussels, pp 65-77

58. Dey PP, Pramanik S, Giri BC, Smarandache F (2017) Bipolar neutrosophic projection based models for solving multi-attribute decision-making problems. Neutrosophic Sets Syst 15:70-79. https://doi.org/10.5281/zenodo.570936

59. Pramanik S, Dalapati S, Alam S, Roy TK (2018) VIKOR based MAGDM strategy under bipolar neutrosophic set environment. Neutrosophic Sets Syst 19:57-69. https://doi.org/10.5281/zenodo. 1235341

60. Pramanik S, Dalapati S, Alam S, Roy TK (2018) TODIM method for group decision making under bipolar neutrosophic set environment. In: Smarandache F, Pramanik S (eds) New trends in neutrosophic theory and applications. Pons Editions, Brussels, pp $140-155$

61. Ulucay V, Kilic A, Yildiz I, Sahin M (2018) A new approach for multi-attribute decision making problems in bipolar neutrosophic sets. Neutrosophic Sets Syst 23(1):142-159. https://doi.org/ 10.5281/zenodo.2154873

62. Pramanik S, Dey PP, Smarandache F, Ye J (2018) Cross entropy measures of bipolar and interval bipolar neutrosophic sets and their application for multi-attribute decision-making. Axioms 7(21):1-25. https://doi.org/10.3390/axioms7020021

63. Pramanik S, Dey PP, Smarandache F (2018) Correlation coefficient measures of interval bipolar neutrosophic sets for solving multi-attribute decision making problems. Neutrosophic Sets Syst 19:70-79. https://doi.org/10.5281/zenodo.1235151

64. Pramanik S, Dalapati S, Alam S, Roy TK, Smarandache F (2017) Neutrosophic cubic MCGDM method based on similarity measure. Neutrosophic Sets Syst 16:44-56. https://doi.org/10.5281/zenodo. 831934

65. Pramanik S, Dey PP, Smarandache F (2017) An extended TOPSIS for multi-attribute decision making problems with neutrosophic cubic information. Neutrosophic Sets Syst 17:20-28. https://doi. org/10.5281/zenodo.1012217

66. Pramanik S, Dalapati S, Alam S, Roy TK (2018) NC-VIKOR based MAGDM strategy under neutrosophic cubic set environment. Neutrosophic Sets Syst 20:95-108. https://doi.org/10.5281/ zenodo. 1235367

67. Dalapati S, Pramanik S (2018) A revisit to NC-VIKOR based MAGDM strategy in neutrosophic cubic set environment. Neutrosophic Sets Syst 21:131-141. https://doi.org/10.5281/zenodo. 1408665

68. Biswas P, Pramanik S, Giri BC (2016) Aggregation of triangular fuzzy neutrosophic set information and its application to multi-attribute decision making. Neutrosophic Sets Syst 12:20-40. https://doi.org/10.5281/zenodo.571125

69. Abdel-Basset M, Mohamed M, Hussien Sangaiah AK (2018) A novel group decision-making model based on triangular neutrosophic numbers. Soft Comput 22(20):6629-6643. https://doi.org/ 10.1007/s00500-017-2758-5 
70. Biswas P, Pramanik S, Giri BC (2015) Cosine similarity measure based multi-attribute decision-making with trapezoidal fuzzy neutrosophic numbers. Neutrosophic Sets Syst 8:46-56. https://doi. org/10.5281/zenodo.571274

71. Biswas P, Pramanik S, Giri BC (2018) Multi-attribute group decision making based on expected value of neutrosophic trapezoidal numbers. In: Smarandache F, Pramanik S (eds) New trends in neutrosophic theory and applications, vol 2. Pons Editions, Brussels, pp 103-124

72. Sahin M, Ulucay V, Broumi S (2018) Bipolar neutrosophic soft expert set theory. In: Smarandache F, Pramanik S (eds) New trends in neutrosophic theory and applications, vol 2. Pons Editions, Brussels, pp 275-288

73. Banerjee D, Pramanik S, Giri BC (2017) GRA for multi attribute decision making in neutrosophic cubic set environment. Neutrosophic Sets Syst 15:60-69. https://doi.org/10.5281/zenodo.570938

74. Biswas P, Pramanik S, Giri BC (2019) Non-linear programming approach for single-valued neutrosophic TOPSIS method. New Math Nat Comput 15(2):1-20. https://doi.org/10.1142/ S1793005719500169

75. Pramanik S, Roy TK (2014) Neutrosophic game theoretic approach to Indo-Pak conflict over Jammu-Kashmir. Neutrosophic Sets Syst 2:82-101. https://doi.org/10.5281/zenodo.571510

76. Zhang M, Zhang L, Cheng HD (2010) A neutrosophic approach to image segmentation based on watershed method. Signal Process 90(5):1510-1517. https://doi.org/10.1016/j.sigpro.2009.10.021

77. Mondal K, Pramanik S (2014) Multi-criteria group decision making approach for teacher recruitment in higher education under simplified neutrosophic environment. Neutrosophic Sets Syst 6:28-34. https://doi.org/10.5281/zenodo.571479

78. Ye J (2015) Trapezoidal neutrosophic set and its application to multiple attribute decision making. Neural Comput Appl 26(5):1157-1166. https://doi.org/10.1007/s00521-014-1787-6

79. Ye J (2017) Some weighted aggregation operator of trapezoidal neutrosophic number and their multiple attribute decision making method. Informatica 28(2):387-402. https://doi.org/10.5281/ zenodo. 23073

80. Deli I, Subas Y (2016) A ranking method of single valued neutrosophic numbers and its applications to multi-attribute decision making problems. Int J Mach Learn Cybern 8(4):1309-1322. https://doi.org/10.1007/s13042016-0505-3

81. Liang RX, Wang JQ, Zhang HY (2018) A multi-criteria decision making method based on single valued trapezoidal neutrosophic preference relation with complete weight information. Neural Comput Appl 30(11):3383-3398. https://doi.org/10.1007/s00521017-2925-8

82. Biswas P, Pramanik S, Giri BC (2016) Value and ambiguity index based ranking method of single-valued trapezoidal neutrosophic numbers and its application to multi-attribute decision making. Neutrosophic Sets Syst 12:127-138. https://doi.org/10. 5281/zenodo.571154
83. Biswas P, Pramanik S, Giri BC (2018) TOPSIS strategy for multiattribute decision making with trapezoidal numbers. Neutrosophic Sets Syst 19:29-39. https://doi.org/10.5281/zenodo.1235335

84. Pramanik S, Mallick R (2018) VIKOR based MAGDM strategy with trapezoidal neutrosophic number. Neutrosophic Sets Syst 22:118-130. https://doi.org/10.5281/zenodo.2160840

85. Giri BC, Molla MU, Biswas P (2018) TOPSIS method for MADM based on interval trapezoidal neutrosophic numbers. Neutrosophic Sets Syst 22:151-167. https://doi.org/10.5281/zenodo.2160749

86. Gomes LFAM, Lima MMPP (1991) TODIM: basics and application to multicriteria ranking of projects with environmental impacts. Found Comput Decis Sci 16:113-127

87. Qin Q, Liang F, Li L, Wangchen Y, Yu GF (2017) A TODIM-based multi-criteria group decision making with triangular intuitionistic fuzzy numbers. Appl Soft Comput 55:93-107. https://doi.org/10. 1016/j.asoc.2017.01.041

88. Wang JQ, Li XE (2015) TODIM method with multi-valued neutrosophic set. Control Decis 30(6):1139-1142. https://doi.org/10. 13195/j.kzyjc.2014.0467

89. Zhang M, Liu P, Shi L (2016) An extended multiple attribute group decision-making TODIM method based on neutrosophic number. J Intell Fuzzy Syst 30:1773-1781. https://doi.org/10.3233/ IFS-151889

90. Pramanik S, Dalapati S, Alam S, Roy TK (2017) NC-TODIMbased MAGDM under a neutrosophic cubic set environment. Information 8(4):149. https://doi.org/10.3390/info8040149

91. Pramanik S, Dalapati S, Alam S, Roy TK (2018) TODIM method for group decision making under bipolar neutrosophic set environment. In: Smarandache F, Pramanik S (eds) New trends in neutrosophic theory and applications, vol 2. Pons Editions, Brussels, pp 140-155

92. Mondal K, Pramanik S (2014) Intuitionistic fuzzy multicriteria group decision making approach to quality-brick selection problem. J Appl Quant Methods 9(2):35-50

93. Mondal K, Pramanik S (2015) Neutrosophic decision making model for clay-brick selection in construction field based on grey relational analysis. Neutrosophic Sets Syst 9:64-71. https://doi. org/10.5281/zenodo. 34864

94. Pramanik S, Mukhopadhyaya D (2011) Grey relational analysis based intuitionistic fuzzy multi criteria group decision-making approach for teacher selection in higher education. Int J Comput Appl 34(10):21-29. https://doi.org/10.5120/4138-5985

95. Dey PP, Pramanik S, Giri BC (2015) Multi-criteria group decision making in intuitionistic fuzzy environment based on grey relational analysis for weaver selection in Khadi institution. J Appl Quant Methods 10(4):1-14

Publisher's Note Springer Nature remains neutral with regard to jurisdictional claims in published maps and institutional affiliations 